\title{
CADÊ MEU QUADRO? \\ EVIDÊNCIAS SOBRE O ESTUDO DO ENSINO DE ENGENHARIA DE PRODUÇÃO
}

\author{
José Augusto Oliveira (UNIVERSIDADE FEDERAL DE LAVRAS) \\ jaugusto.oliveira@outlook.com \\ Letícia Bettoni Siqueira (UNIVERSIDADE FEDERAL DE LAVRAS) \\ leticialbs@hotmail.com \\ Izadora Ribeiro e Garcia de Oliveira (UNIVERSIDADE FEDERAL DE LAVRAS) \\ izadora_rgo@hotmail.com \\ Lauriene Teixeira Santos (UNIVERSIDADE FEDERAL DE LAVRAS) \\ lauriene.tsantos@gmail.com \\ Augusto Chaves Martins (UNIVERSIDADE FEDERAL DE LAVRAS) \\ augustoch@live.com
}

\section{Resumo}

Frente a necessidade de construir cursos de graduação que reduzam as distâncias entre academia e prática, e ao mesmo tempo desenvolvam alunos conforme as necessidades de mercado, este artigo teve como objetivo identificar quais são as técnicas e métodos não tradicionais que logram êxito no ambiente de ensino da Engenharia de Produção. Para tanto, empreendeu-se um estudo de revisão nas bases de conhecimento Web of Science e Scopus. Foram identificadas uma série de técnicas e métodos que vêm sendo aplicados nas salas de aula de Engenharia de Produção, destacando-se: ao learnstruments, as simulações computacionais e não computacionais, o Project Based Learning, o aprendizado baseado em problemas e projetos, os casos didáticos, os games e os kaizens.

\section{Palavras-Chaves: Ensino de Engenharia de Produção. Metodologias Ativas. Docência.}

\section{Introdução}

Segundo reportagem veiculada pelo Jornal O Globo, em Abril de 2019, a recuperação de setores estratégicos como petróleo e habitação está favorecendo o crescimento dos cursos de engenharia no Brasil (O GLOBO, 2019). Se por um lado, alunos buscam estes cursos com o objetivo de se qualificar para o mercado de trabalho, em tempos de transformação digital e Indústria 4.0, a adequação das salas de aulas tradicionais não constitui apenas um diferencial estratégico, mas sim uma necessidade competitiva.

Para além da visão tradicional de Universidades como centros de criação de conhecimento, destaca-se o importante papel dessas instituições na formação instrumental e cidadã dos indivíduos (GOERGEN, 2010). Desta forma, o ato de ensinar pode ser ampliado, envolvendo 
uma série de articulações e conexões entre cadeiras teóricas, didáticas e práticas (CRUZ, 2017) que moldam a dinâmica docente.

Contudo, nota-se que na maioria dos cursos de engenharia no Brasil, inclusive nos Cursos de Engenharia de Produção, as técnicas de ensino tradicionais, ou seja, aulas formatadas no formato expositivo, onde os professores expõem o conhecimento sem exigir grande internalização ou reflexão dos alunos, ainda representam a realidade da maioria das instituições de ensino brasileiras.

Desta forma, frente a necessidade de refletir o modelo tradicional de ensino, neste artigo buscase identificar quais são as técnicas e métodos não tradicionais que logram êxito no ambiente de ensino da Engenharia de Produção.

Espera-se que os resultados alcançados contribuam para a reflexão da prática docente nos cursos de Engenharia de Produção, apontando possíveis técnicas que podem e devem ser aplicadas em salas de aula para efetivar o senso crítico dos alunos, permitindo uma maior conexão entre a teoria e o campo empírico. Em outras palavras, a adoção de técnicas e metodologias ativas ainda nas salas de aula durante a graduação pode reduzir a distância entre academia e prática e fomentar a formação de um corpo discente que veja sentido nas atividades desenvolvidas em sala de aula.

\section{Referencial Teórico}

A demanda por inovações pedagógicas em todos os níveis de ensino é crescente (MACHADO, 2008). Sendo assim, é necessário que as unidades educacionais consigam superar as expectativas da sociedade atual através da aplicação de novas técnicas e métodos ao ensinar. Segundo Cruz (2017), existem inúmeros fatores que implicam no ato de ensinar, pois requer uma variada e complexa articulação de saberes teóricos, didáticos, científicos e pedagógicos.

A docência é uma das mais antigas ocupações do mundo e, além de impactar nas funções sociotécnicas dos indivíduos, o ensino exerce impacto também na distribuição dos conhecimentos e competências entre os membros de uma sociedade (TARDIF e LESSARD, 2005). Possuir uma boa didática é substancial para um bom ensino. Segundo Rodrigues, Moura e Testa (2011, p.1) "a didática não objetiva apenas o conhecimento pelo conhecimento, mas procura aplicar os seus próprios princípios à finalidade concreta que é a instrução educativa."

Dessa forma, destaca-se que as Universidades como centros de criação de conhecimento, desempenham um papel importante na formação instrumental e cidadã dos indivíduos 
(GOERGEN, 2010). Ainda segundo esse autor, grande parte das universidades tem enfatizado o ensino instrumental com vista a capacitar seus estudantes para se adaptarem a realidade socioeconômica de onde vivem, e, consequentemente tem desvalorizado a formação de cidadãos autônomos com capacidades críticas e reflexivas.

Anastasiou (2004) já questionava as estratégias ultrapassadas utilizadas na sala de aula dos Institutos de Ensino Superior (IES), mesmo frente as mudanças constantes dos alunos, bem como de suas histórias e experiências. Da mesma forma, Berbel (2011) afirma que a complexidade crescente dos diversos setores no âmbito mundial exige que as capacidades humanas de sentir, pensar e agir sejam desenvolvidas nos estudantes com o objetivo de conseguirem sua autonomia, e isso pode ser alcançado principalmente através da aplicação de metodologias ativas durante as aulas.

Muitos estudos têm sido realizados com objetivo de desenvolver novos modelos de ensino e aprendizagem que gerem resultados mais efetivos para os alunos de universidades (MONTEIRO et al., 2017). Os autores ainda alegam que muitas vezes os estudantes não recebem um conteúdo técnico capaz de auxiliá-los em seus campos de atuação profissional, sendo assim privados da oportunidade de desenvolver suas habilidades ao longo de seus programas acadêmicos.

Dessa forma, é importante destacar que ao se aplicar novos instrumentos de aprendizagem nas salas de aulas nos cursos de graduação, em destaque nos cursos mais técnicos como a Engenharia, os estudantes poderão obter uma aprendizagem de uma forma mais fácil e mais interativa, além de conseguir abordar os aspectos cognitivos, domínios afetivos e psicomotores dos mesmos (MENN et al., 2018).

\section{Métodos}

Para operacionalização desta pesquisa foi realizada uma revisão sistemática da literatura. Conforme apontado por Sampaio e Mancini (2007), este tipo de investigação utiliza como fonte de dados a literatura sobre determinado tema e possibilita que informações presentes em um conjunto de trabalhos sejam agrupadas em relação a uma estratégia de intervenção específica. Com o objetivo de garantir o rigor metodológico e reduzir os vieses de seleção dos artigos, foram obedecidos os itens propostos pela metodologia PRISMA - Preferred Reporting Items for Systematic Reviews and Meta-Analyses verificados em Moher et al., (2009). 


\subsection{Formulação da questão de pesquisa}

A questão de pesquisa investigada neste trabalho foi construída a partir do modelo PICO, que representa um acrônimo para Population, Intervention, Comparison, Outcome. Conforme Santos, Pimenta, \& Nobre (2007), a estratégia PICO amplia a recuperação de evidências nas bases de dados e direciona o foco da pesquisa, evitando assim buscas desnecessárias. Portanto, as estratégias de busca foram operacionalizadas em torno da seguinte questão: Quais são as técnicas de ensino não tradicionais aplicadas no ensino de engenharia de produção?

\subsection{Estratégia de busca}

Para identificar os artigos relacionados à questão proposta, foram adotadas duas frentes de seleção, executadas em janeiro de 2020. Na frente de seleção 01 foram mapeados os artigos presentes na base Web of Science correspondentes à string $T I=$ "production engineering” AND $T I=$ (teach* or learn* or "active methodolog*” or pbl or "digital education”). Na segunda frente de seleção foram selecionados os artigos indexados na base Scopus referentes à string: TITLE ("production engineering") AND TITLE (teach* or learn* or "active methodolog*” or pbl or "digital education").

\subsection{Critérios de elegibilidade}

Foram considerados elegíveis os estudos que: (i) foram publicados nos idiomas inglês, português ou espanhol e (ii) estivessem disponíveis em texto integral. Com o intuito de mapear o maior número de evidências científicas relacionadas a questão de pesquisa investigada nesta revisão, não houve delimitação quanto a data de publicação dos trabalhos. Após exclusão dos trabalhos em duplicidade, foi realizada a leitura dos resumos dos artigos selecionados, seguindo as etapas de seleção de evidências científicas em revisões sistemáticas propostas em Pereira \& Galvão (2014) e Sampaio \& Mancini (2007).

Foram excluídos os estudos que não disponibilizavam os resumos para leitura e que fugiam do escopo temático proposto.

Após as consultas nas bases foram identificados 30 trabalhos (09 na base Web of Science e 21 na base Scopus), sendo excluídos 5 trabalhos em duplicidade. Assim, foram selecionados 25 artigos para avaliação dos títulos e resumos, destes, 05 foram excluídos após a leitura dos resumos. Foi realizada a leitura integral dos 20 estudos restantes, sendo excluídos 03 artigos que não se enquadraram no escopo investigado pela questão de pesquisa. Por fim, 17 artigos foram aceitos e incluídos nesta revisão sistemática (Quadro 1). A Figura 01 representa a síntese do processo de seleção de artigos. 
Figura 1. Fluxo de seleção de artigos na revisão sistemática sobre alianças estratégicas e inovação baseado na recomendação PRISMA
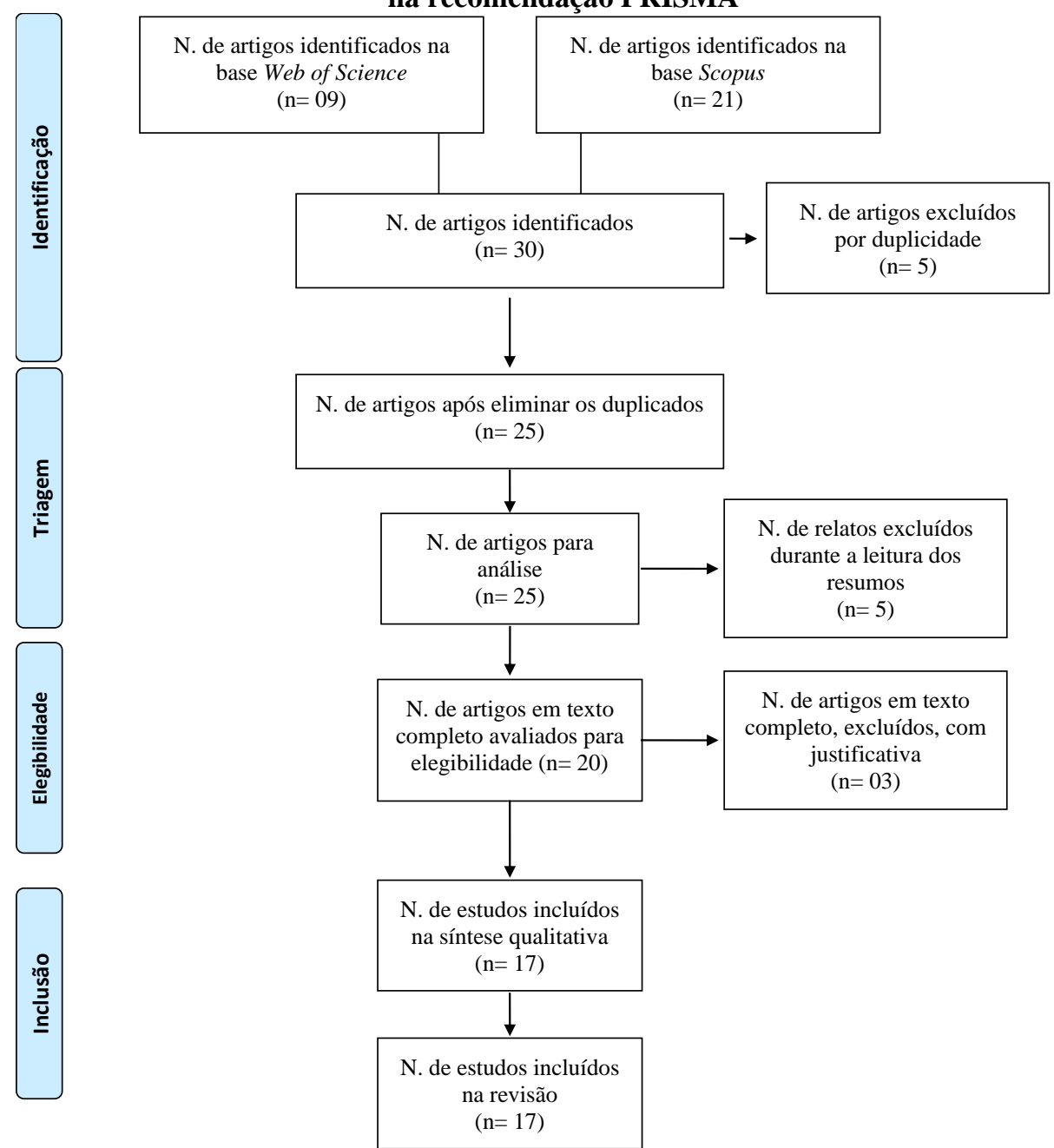

Fonte: Dados da Pesquisa (2020)

Quadro 1. Relação de artigos selecionados para síntese qualitativa

\begin{tabular}{|c|c|c|c|}
\hline $\mathbf{N}^{\mathbf{o}}$ & Autor/Ano & Artigo & Journal/Conference \\
\hline 1 & (MARIANO et al., 2018) & $\begin{array}{c}\text { Background factors in the choice of the } \\
\text { production engineering course with active } \\
\text { methodology: A study through structural } \\
\text { equations }\end{array}$ & $\begin{array}{l}\text { International Symposium on } \\
\text { Project Approaches in } \\
\text { Engineering Education }\end{array}$ \\
\hline 2 & (MENN et al., 2018) & $\begin{array}{l}\text { Learnstruments: Learning-conducive } \\
\text { artefacts to foster learning productivity in } \\
\text { production engineering }\end{array}$ & CIRP Annals \\
\hline 3 & (ELY; TARONI, 2017) & $\begin{array}{l}\text { Simulation for teaching the production cell } \\
\text { concept in civil production engineering }\end{array}$ & $\begin{array}{l}\text { Simulation for teaching the } \\
\text { production cell concept in civil } \\
\text { production engineering }\end{array}$ \\
\hline 4 & $\begin{array}{l}\text { (MONTEIRO et al., } \\
\text { 2017) }\end{array}$ & $\begin{array}{c}\text { A Project-based Learning curricular } \\
\text { approach in a Production Engineering } \\
\text { Program }\end{array}$ & Production \\
\hline 5 & $\begin{array}{c}(\text { SILVA; } \\
\text { KORZENOWSKI; } \\
\text { DALL'AGNOL, 2016) }\end{array}$ & $\begin{array}{l}\text { Engenharia de Produção no Norte do } \\
\text { Brasil: As competências de ensino na visão } \\
\text { dos coordenadores de curso }\end{array}$ & Espacios \\
\hline 6 & $\begin{array}{l}\text { (BALVE; ALBERT, } \\
\text { 2015) }\end{array}$ & $\begin{array}{l}\text { Project-based learning in production } \\
\text { engineering at the heilbronn learning } \\
\text { factory }\end{array}$ & Procedia CIRP \\
\hline
\end{tabular}




\begin{tabular}{|c|c|c|c|}
\hline 7 & $\begin{array}{l}\text { (GIROTTI; MESQUITA, } \\
\text { 2015) }\end{array}$ & $\begin{array}{l}\text { Simulação e estudos de caso no ensino de } \\
\text { planejamento e controle da produção: um } \\
\text { survey com professores da engenharia de } \\
\text { produção }\end{array}$ & Production \\
\hline 8 & (BLUME et al., 2015) & $\begin{array}{l}\text { Die lernfabrik-research-based learning for } \\
\text { sustainable production engineering }\end{array}$ & Procedia CIRP \\
\hline 9 & $\begin{array}{c}\text { (SOUTO-IGLESIAS et } \\
\text { al., 2013) }\end{array}$ & $\begin{array}{l}\text { Integrated Learning of Production } \\
\text { Engineering Software Applications in a } \\
\text { Shipbuilding Context }\end{array}$ & $\begin{array}{l}\text { International Journal of } \\
\text { Engineering Education }\end{array}$ \\
\hline 10 & $\begin{array}{l}\text { (HAUGE; RIEDEL, } \\
\text { 2012) }\end{array}$ & $\begin{array}{l}\text { Evaluation of simulation games for } \\
\text { teaching engineering and manufacturing }\end{array}$ & Procedia Computer Science \\
\hline 11 & $\begin{array}{l}\text { (TERKOWSKY et al., } \\
\text { 2011) }\end{array}$ & $\begin{array}{c}\text { Tele-operated laboratories for online } \\
\text { production engineering education platform } \\
\text { for e-learning and telemetric } \\
\text { experimentation (PeTEX) }\end{array}$ & $\begin{array}{c}\text { International Journal of Online } \\
\text { Engineering }\end{array}$ \\
\hline 12 & $\begin{array}{l}\text { (SOUTO-IGLESIAS et } \\
\text { al., 2011) }\end{array}$ & $\begin{array}{l}\text { Integrated Learning of Computer } \\
\text { Applications for Production Engineering }\end{array}$ & $\begin{array}{l}\text { Inted2011: 5Th International } \\
\text { Technology, Education and } \\
\text { Development Conference }\end{array}$ \\
\hline 13 & $\begin{array}{l}\text { (PRINCE; FELDER, } \\
\text { 2006) }\end{array}$ & $\begin{array}{c}\text { Inductive teaching and learning methods: } \\
\text { Definitions, comparisons, and research } \\
\text { bases. }\end{array}$ & $\begin{array}{l}\text { Journal of engineering } \\
\text { education }\end{array}$ \\
\hline 14 & (KU; FULCHER, 2011) & $\begin{array}{c}\text { The process of updating engineering } \\
\text { management science in an Australian } \\
\text { regional university excellence in } \\
\text { developing e-learning }\end{array}$ & $\begin{array}{l}\text { Proceedings of the } 2011 \\
\text { International MultiConference } \\
\text { of Engineers and Computer } \\
\text { Scientists (IMECS 2011). }\end{array}$ \\
\hline 15 & $\begin{array}{l}\text { (TORRE; RODRÍGUEZ, } \\
\text { 2010) }\end{array}$ & $\begin{array}{l}\text { Aplicación de nuevas prácticas educativas } \\
\text { tipo kaizen para la enseñanza- } \\
\text { Aprendizaje en ingeniería de producción }\end{array}$ & $\begin{array}{l}\text { Revista de la Facultad de } \\
\text { Ingeniería U.C.V }\end{array}$ \\
\hline 16 & $\begin{array}{l}\text { (HERZOG; TRIER; } \\
\text { SIECK, 2006) }\end{array}$ & $\begin{array}{l}\text { Production engineering for video based e- } \\
\text { and m-learning content }\end{array}$ & $\begin{array}{l}\text { 10th Baltic Region Seminar on } \\
\text { Engineering Education }\end{array}$ \\
\hline 17 & (STEIL; BARCIA, 2006) & $\begin{array}{l}\text { Atitudes de alunos e professores com } \\
\text { relação a cursos de mestrado em } \\
\text { engenharia de produção a distância }\end{array}$ & Gestao e Producao \\
\hline
\end{tabular}

Fonte: Dados da Pesquisa (2020)

\section{Resultados}

Mariano et al. (2018) investigaram quais os fatores influenciam a escolha de alunos por cursos de Graduação em Engenharia de Produção que utilizam metodologias ativas. A partir de um estudo realizado com uma amostra composta por 152 estudantes do curso de Engenharia de Produção da Universidade de Brasília, esses autores apontam que dois fatores tem forte influência para escolha de cursos desta natureza: os fatores econômicos e psicológicos. Enquanto a influência dos fatores econômicos reside principalmente na percepção do custo benefício da graduação, os fatores psicológicos englobam a percepção das habilidades e conhecimentos desenvolvidos ao longo da formação discente. Apesar do apelo prático e comercial das metodologias ativas, destaca-se a compreensão das técnicas que são aplicadas, em profundidade, é fundamental para maximizar o aprendizado e a satisfação dos alunos que são instruídos sob o prisma deste método de ensino. 
Os Learnstruments, que são instrumentos que demonstram automaticamente suas funcionalidades aos alunos, são exemplos de técnicas não habituais que podem ser aplicadas para o ensino de Engenharia de Produção. Menn et al. (2018) desenvolveram um Learnstrument com o objetivo de realizar soluções de design com impactos significativos na produtividade do aprendizado e ensino, oferecendo para academia uma nova morfologia. Para construção destes instrumentos devem ser considerados tanto os aspectos didáticos, que compreendem tópicos como os objetivos do ensino, as competências, a motivação externa, a autonomia para o aprendizado e o contexto didático; e os aspectos técnicos, que compreendem tópicos como a tangibilidade, complexidade, mobilidade, abstração e valor adicional.

Mesmo em cursos de Engenharia de Produção direcionados para um algum eixo temático, como por exemplo nos Cursos de Engenharia de Produção Civil, a adoção de métodos de ensino não tradicionais vêm ganhando espaço e alcançando bons resultados. Neste contexto, Ely e Taroni (2017) destacam a utilização de simulações como ferramentas facilitadoras no processo de ensino. A realidade prática destas simulações pode ser destacada como um dos principais ganhos na aplicação da técnica. Os autores mostram que as simulações não são, obrigatoriamente, realizadas em formato digital e apontam que devem ser realizadas de forma sequencial para promoção do ensino de forma contínua e gradual.

Girotti e Mesquita (2015), em um survey aplicado à professores do curso de engenharia de produção, mostram que $85 \%$ desses acreditam que a utilização de simulações com softwares contribui para a melhoria do aprendizado. Nesse sentido, para estruturação das simulações surgem os casos didáticos que trazem para o meio acadêmico fontes de informações reais ou simuladas, que tem como objetivo específico a aprendizagem e o desenvolvimento de habilidades de análise, comunicação e resolução de problemas.

A metodologia Project Based Learning (PBL), permite que aos alunos desenvolvam suas competências técnicas através de situações que envolvem a resolução de problemas reais. Citase como exemplos de PBL o aprendizado por inquérito, o aprendizado baseado em problemas, o aprendizado baseado em projetos, o ensino baseado em casos, o aprendizado de descoberta e o ensino just in time (Prince e Felder, 2006). Monteiro et al. (2017) apresentam a experiência de um curso de graduação brasileiro que foi estruturado sobre os pilares da PBL; os autores destacam que essa metodologia estimula o desenvolvimento das habilidades sociais dos alunos, expondo-os a um ambiente desafiador, além de aproximá-los da prática uma vez que os resultados de cada projeto são apresentados e posteriormente implantados por agentes externos. Esses autores destacam que técnicas ativas como a PBL fortalecem o envolvimento dos alunos 
com discentes e docentes de outros cursos, aumentando a integração e promovendo o desenvolvimento de habilidades mais holísticas (Soft Skills).

Balve e Albert (2015) compartilham as experiências de um curso de engenharia de produção da Heilbronn University (Universidade Alemã), também estruturado sob o prisma da PBL. Os autores destacam que a adoção da PBL permite que melhorar as habilidades sociais dos alunos, como a capacidade de comunicar com êxito as questões técnicas, cooperar efetivamente com parceiros internos e a capacidade geral de colocar a teoria em prática.

Em um estudo desenvolvido em cursos de Engenharia de Produção da região Norte do Brasil, Silva, Korzenowski e Dall'agnol (2016) apontam que cinco níveis de habilidades são necessárias para formação discente na visão dos coordenadores: (i) identificar problemas, trabalho em equipe; (ii) iniciativa, língua estrangeira, resolver problemas, pensamento sistêmico; (iii) empreendedor, comunicação oral, domínio de técnicas computacionais; (iv) leitura e interpretação, visão crítica e ordem de grandezas e (v) comunicação escrita. Para esses autores, as grades de cada curso devem ser compostas conforme o mercado de atuação local, ou seja, a reprodução total ou parcial de currículos de outras regiões pode nem sempre ser a melhor opção.

A estruturação de games também pode maximizar o aprendizado em sala de aula (HAUGE; RIEDEL, 2012). Para esses autores, os custos elevados para o desenvolvimento e a necessidade de facilitadores especializados para execução das sessões dos jogos representam as principais desvantagens deste tipo de abordagem. O gerenciamento de riscos e a o desenvolvimento de novos produtos são exemplos de atividades que podem ser desenvolvidas e aperfeiçoadas com a utilização de games.

Algumas técnicas de gerenciamento e qualidade que são aprendidas durante a graduação em Engenharia Civil também podem constituir métodos não tradicionais de ensino. Entre essas, destaca-se a utilização do Kaizen como ferramenta de ensino (TORRE; RODRÍGUEZ, 2010). Para esses autores, a utilização destas técnicas promove o pensamento crítico e a aprendizagem do aluno.

Nota-se, portanto, que diversas técnicas foram evidenciadas durante a análise qualitativa dos artigos que compõem o corpus deste estudo. A figura 02 representa o esforço de síntese desenvolvido: 
Figura 02: Métodos ativos aplicados para o ensino de Engenharia de Produção

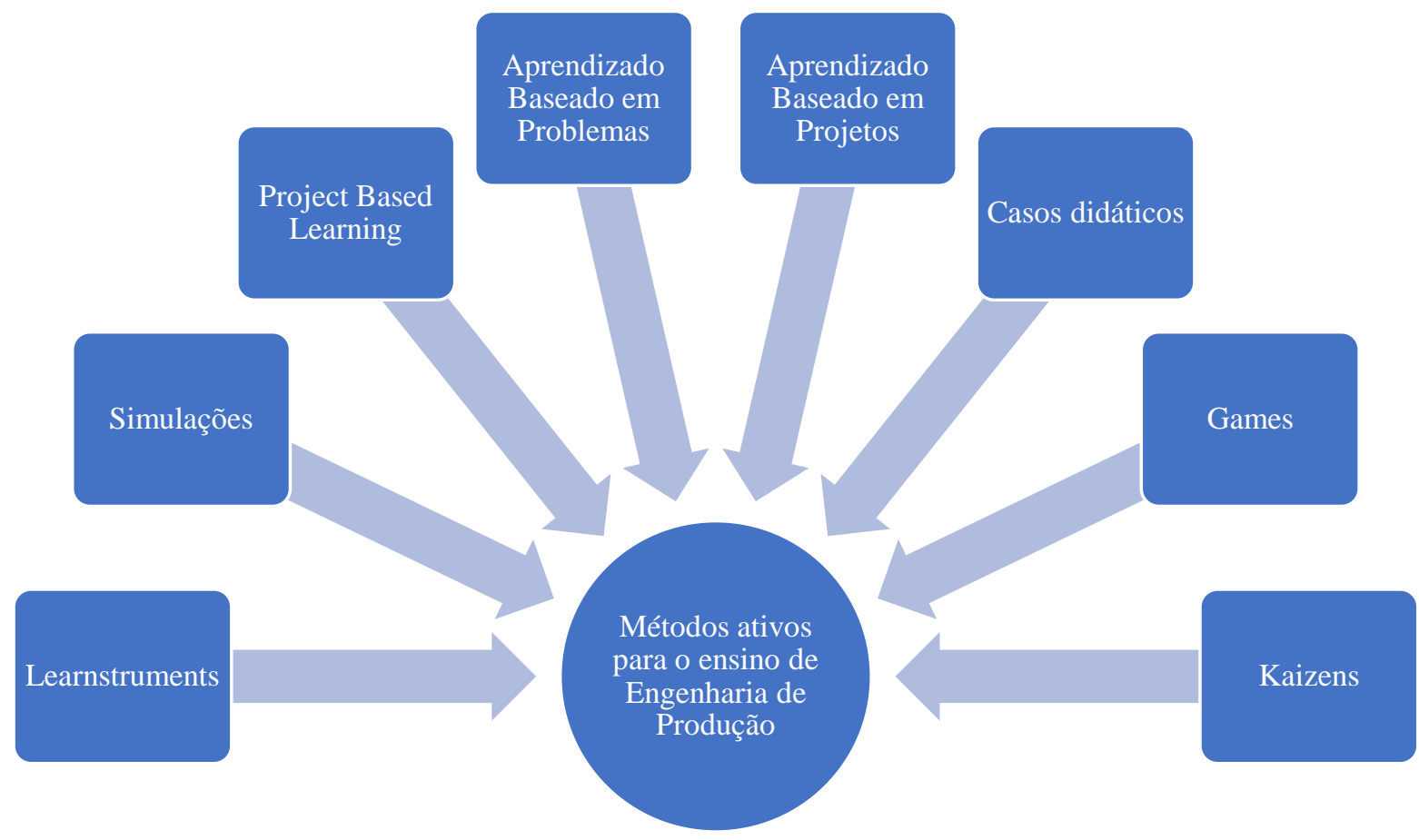

Fonte: Dados da Pesquisa (2020)

\section{Considerações Finais}

A revisão sistemática empreendida neste artigo alcança o objetivo proposto ao identificar quais são as técnicas de ensino não tradicionais aplicadas para o ensino de Engenharia de Produção. Entre os artigos incluídos na síntese qualitativa foi evidenciada a utilização de técnicas como a learnstruments, as simulações computacionais e não computacionais, o Project Based Learning, o aprendizado baseado em problemas e projetos, os casos didáticos, os games e os kaizens.

Apesar da pequena quantidade de artigos mapeados, destaca-se a preocupação da academia brasileira para o estudo do ensino de Engenharia de Produção, uma vez que quatro dos dezessete trabalhos selecionados retratam o contexto brasileiro. Em essência, a utilização de técnicas não convencionais para o ensino maximiza a capacidade geral do aluno em colocar a teoria em prática, além de constituir um diferencial competitivo da universidade, o que influencia a decisão do discente pela escolha do curso.

Por fim, recomendam-se trabalhos futuros que consultem outras bases de conhecimento durante o processo de escolha das evidências científicas a fim de ampliar o alcance do corpus discutido neste artigo. Sugere-se também que este trabalho de revisão seja periodicamente revisado a fim 
de verificar novas tendências e práticas relacionadas ao estudo do ensino de Engenharia de Produção.

\section{REFERÊNCIAS}

ANASTASIOU, Léa das Graças Camargos et al. Estratégias de ensinagem. Processos de ensinagem na universidade. Pressupostos para as estratégias de trabalho em aula, v. 3, p. 67-100, 2004.

BALVE, P.; ALBERT, M. Project-based learning in production engineering at the heilbronn learning factory. Procedia CIRP, v. 32, n. Clf, p. 104-108, 2015.

BERBEL, Neusi Aparecida Navas. As metodologias ativas e a promoção da autonomia de estudantes. Semina: Ciências Sociais e Humanas, v. 32, n. 1, p. 25-40, 2011.

BLUME, S. et al. Die lernfabrik-research-based learning for sustainable production engineering. Procedia CIRP, v. 32, n. Clf, p. 126-131, 2015.

CRUZ, Giseli Barreto da. Didática e docência no ensino superior. Revista Brasileira de Estudos Pedagógicos, v. 98, n. 250, p. 672-689, 2017.

ELY, D. M.; TARONI, A. C. B. Simulation for teaching the production cell concept in civil production engineering. Proceedings of the European Modeling and Simulation Symposium, n. 2006, p. 159-165, 2017.

GIROTTI, L. J.; MESQUITA, M. A. DE. Simulação e estudos de caso no ensino de planejamento e controle da produção: um survey com professores da engenharia de produção. Production, v. 26, n. 1, p. 176-189, 2015.

GOERGEN, Pedro. Educação instrumental e formação cidadã: observações críticas sobre a pertinência social da universidade. Educar em Revista, n. 37, p. 59-76, 2010.

HAUGE, J. B.; RIEDEL, J. C. K. H. Evaluation of simulation games for teaching engineering and manufacturing. Procedia Computer Science, v. 15, p. 210-220, 2012.

HERZOG, M. A.; TRIER, M.; SIECK, J. Production engineering for video based e- and m-learning content. 10th Baltic Region Seminar on Engineering Education, p. 4-6, 2006.

KU, H.; FULCHER, R. The process of updating engineering management science in an Australian regional university excellence in developing e-learning. Proceedings of the 2011 International MultiConference of Engineers and Computer Scientists (IMECS 2011), v. 32, n. 5, p. 527-538, 2011.

MACHADO, Nílson José. Imagens do conhecimento e ação docente no ensino superior. 2008.

MARIANO, A. M. et al. Background factors in the choice of the production engineering course with active methodology: A study through structural equations. International Symposium on Project Approaches in Engineering Education, v. 8, n. March, p. 577-585, 2018.

MENN, Jan Philipp et al. Learnstruments: Learning-conducive artefacts to foster learning productivity in production engineering. CIRP Annals, v. 67, n. 1, p. 459-462, 2018.

MOHER, D. et al. Preferred reporting items for systematic reviews and meta-analyses: The PRISMA statement. PLoS Medicine, v. 6, n. 7, 2009.

MONTEIRO, S. B. S. et al. A Project-based Learning curricular approach in a Production Engineering Program. Producao, v. 27, n. Specialissue, p. 1-12, 2017.

O GLOBO. Atenta ao mercado, Engenharia se mantém entre os principais cursos. 2019. Disponível em: $<$ https://oglobo.globo.com/sociedade/educacao/enem-e-vestibular/atenta-ao-mercado-engenharia-se-mantementre-os-principais-cursos-23572931>. Acesso em: 15 jan. 2020. 
PEREIRA, M. G.; GALVÃO, T. F. Etapas de busca e seleção de artigos em revisões sistemáticas da literatura. Epidemiologia e Serviços de Saúde, v. 23, n. 2, p. 369-371, 2014.

PRINCE, Michael J.; FELDER, Richard M. Inductive teaching and learning methods: Definitions, comparisons, and research bases. Journal of engineering education, v. 95, n. 2, p. 123-138, 2006.

RODRIGUES, Leude Pereira; MOURA, Lucilene Silva; TESTA, Edimárcio. O tradicional e o moderno quanto a didática no ensino superior. Revista Científica do ITPAC, v. 4, n. 3, p. 1-9, 2011.

SAMPAIO, R.; MANCINI, M. Estudos de revisão sistemática: um guia para síntese criteriosa da evidência científica. Revista Brasileira de Fisioterapia, v. 11, n. 1, p. 83-89, 2007.

SANTOS, C. M. D. C.; PIMENTA, C. A. D. M.; NOBRE, M. R. C. A estratégia PICO para a construção da pergunta de pesquisa e busca de evidências. Rev Latino-am Enfermagem, v. 15, n. 3, p. 2-5, 2007.

SILVA, G. DA C.; KORZENOWSKI, A. L.; DALL'AGNOL, M. Engenharia de Produção no Norte do Brasil: As competências de ensino na visão dos coordenadores de curso. Espacios, v. 37, n. 12, 2016.

SOUTO-IGLESIAS, A. et al. Integrated Learning of Computer Applications for Production Engineering. Inted2011: 5Th International Technology, Education and Development Conference, n. January 2015, p. 3155-3163, 2011.

SOUTO-IGLESIAS, A. et al. Integrated learning of production engineering software applications in a shipbuilding context. International Journal of Engineering Education, v. 29, n. 6, p. 1400-1409, 2013.

STEIL, A. V.; BARCIA, R. M. Atitudes de alunos e professores com relação a cursos de mestrado em engenharia de produção a distância. Gestao e Producao, v. 13, n. 1, p. 141-149, 2006.

TARDIF, Maurice; LESSARD, Claude. O trabalho docente hoje: elementos para um quadro de análise. O trabalho docente: elementos para uma teoria da docência como profissão de interações humanas. Petrópolis: Vozes, p. 15-54, 2005.

TERKOWSKY, C. et al. Tele-operated laboratories for online production engineering education platform for elearning and telemetric experimentation (PeTEX). International Journal of Online Engineering, v. 7, n. SUPPL., p. 37-43, 2011.

TORRE, F.; RODRÍGUEZ, M. Aplicación De Nuevas Prácticas Educativas Tipo Kaizen Para La Enseñanza Aprendizaje En Ingeniería De Producción Implementation of New Kaizen Type Educational Practices for Teaching - Learning in Production Engineering. Revista de la Facultad de Ingeniería U.C.V, v. 25, n. 2006, p. 111-116, 2010. 